\title{
NLRP3 inflammasome and lipid metabolism analysis based on UPLC-Q-TOF-MS in gouty nephropathy
}

\author{
YAN-ZI ZHANG, XIAO-LU SUI, YUN-PENG XU, FENG-JUAN GU, AI-SHA ZHANG and JI-HONG CHEN
}

Department of Nephrology, Affiliated Bao'an Hospital of Shenzhen, The Second School of Clinical Medicine, Southern Medical University, Shenzhen, Guangdong 518000, P.R. China

Received October 6, 2018; Accepted April 17, 2019

DOI: $10.3892 / \mathrm{ijmm} .2019 .4176$

\begin{abstract}
To determine the differences in plasma metabolism between healthy patients and patients with hyperuricaemia and gouty nephropathy, the present study identified differentially expressed metabolites associated with gouty nephropathy. Furthermore, the NLRP3 inflammasome signalling pathway in gouty nephropathy was explored, and the mechanism of hyperuricaemia-induced renal damage. Adult male patients examined between July 2016 and June 2017 were selected as the patient cohort for the present study from the Affiliated Bao'an Hospital of Shenzhen, Southern Medical University (Shenzhen, China). These patients were divided into three groups of 30 patients each: Control, hyperuricaemia and gouty nephropathy groups. The expression levels of NLRP3, ASC and caspase- 1 mRNA and protein were detected in peripheral blood mononuclear cells, and the plasma levels of IL-1 $\beta$ and IL-18. Ultra-performance liquid chromatography coupled with quadrupole time-of-flight mass spectrometry was used to determine differential levels of metabolites between patients from different groups, in order to identify potential biomarkers. The expression of the NLRP3 inflammasome in peripheral blood mononuclear cells, and the levels of IL-1 $\beta$ and IL-18 in the plasma were increased in the gouty nephropathy
\end{abstract}

Correspondence to: Dr Ji-Hong Chen, Department of Nephrology, Affiliated Bao'an Hospital of Shenzhen, The Second School of Clinical Medicine, Southern Medical University, 118 Longjing Road, Xinan Street, Bao'an, Shenzhen, Guangdong 518000, P.R. China E-mail: chenjihong0606@hotmail.com

Abbreviations: UPLC-Q-TOF-MS, ultra-performance liquid chromatography coupled with quadrupole time-of-flight mass spectrometry; LC, liquid chromatography; MS, mass spectrometry; NLRP3, Nod-like receptor protein 3; ASC, apoptosis-associated speck like protein; IL-1 $\beta$, interleukin-1 $\beta$; IL-18, interleukin-18; LPC, lysophosphatidylcholine; LPE, lysophosphatidylethanolamine; PC, phosphatidylcholine; PE, phosphatidyl ethanolamine; UDCA, ursodeoxycholic acid; CDCA, chenodeoxycholic acid; TDCA, tauroursodeoxycholic acid; FA, fatty acid; SM, sphingomyelin

Key words: gouty nephropathy, metabolomics, lipid metabolism, Nod-like receptor protein 3 inflammasome group compared with the control and hyperuricaemia groups. In addition, 46 metabolites were identified as potential plasma metabolic biomarkers that were able to distinguish gouty nephropathy from hyperuricaemia. The majority of these metabolites were involved in lipid metabolism, in particular the activity of phospholipase A 2 and $\beta$-oxidation. These data indicated that lipid metabolism and the NLRP3 inflammasome serve a pivotal role in gouty nephropathy. In addition, the results suggested that lipids may mediate the progression of gouty nephropathy through the activity of phospholipase A2, $\beta$-oxidation and activation of the NLRP3 inflammasome.

\section{Introduction}

Uric acid is an independent risk factor for renal progression and the deposition of uric acid in the kidney causes gouty nephropathy. It is hypothesized that inflammatory factors serve an important role in gouty nephropathy (1). Human peripheral blood mononuclear cells (PBMCs) are the key factors in the activation of the immune response. These cells undergo activation, proliferation and differentiation into various cellular subtypes and initiate metabolic reprogramming during these processes. Uric acid crystals have been demonstrated to initiate interleukin-1 $\beta$ (IL-1 $\beta$ )-mediated inflammation via the activation of the NOD-like receptor protein 3 (NLRP3) inflammasome (2), a multi-molecular complex comprised of NLRP3, apoptosis-associated speck like protein (ASC), and caspase-1. NLRP3 is activated primarily in innate immune cells, including macrophages, and by a variety of stimuli including pathogens and danger signals (3). The activation of NLRP3 has been demonstrated to be central to a number of pathological inflammatory conditions $(4,5)$.

Renewed interest in gouty nephropathy has been generated by previous observations indicating that gouty nephropathy is closely associated with hypertension, insulin resistance, obesity, fatty liver disease, cardiovascular disease and other metabolic diseases $(6,7)$. There is a known association between hyperlipidaemia and gout formation (8). A prospective cohort study of 1,606 Chinese patients with gout revealed a significant association with hyperlipidaemia (9). A previous study suggested that a high uric acid concentration resulted in abnormal lipid metabolism and, in turn, these changes in lipid metabolism caused by the presence of abnormal free fatty acids (FAs) were also an important pathological basis 
of hyperuricaemia (10). However, how the activation of the NLRP3 inflammasome and the changes in lipid metabolomics lead to the progression of gouty nephropathy remains unclear.

Therefore, the present study detected the mRNA and protein expression levels of NLRP3, ASC and caspase-1 in peripheral blood mononuclear cells, and the level of the downstream inflammatory factors IL-1 $\beta$ and IL-18 in plasma, in order to evaluate whether the NLRP3 inflammasome was activated in gouty nephropathy. Concomitantly, it was proposed that plasma metabolomics analysis based on ultra-performance liquid chromatography coupled with quadrupole time-of-flight mass spectrometry (UPLC-QTOF/MS) may be used to identify differentially expressed metabolites in gouty nephropathy. Subsequently, the aim of the present study was to combine the analysis of plasma metabolomics with the NLRP3 inflammasome to reveal the mechanism of renal damage induced by hyperuricaemia and to identify novel potential biomarkers for the diagnosis of gouty nephropathy.

\section{Materials and methods}

Patients. The study samples were provided by the Affiliated Bao'an Hospital of Shenzhen, Southern Medical University (Shenzhen, China). The study was approved by the Ethics Committee of the Affiliated Bao'an Hospital of Shenzhen and written informed consent was obtained from all participants. Male patients between the ages of 18-70 years (mean age, $49.56 \pm 11.78$ years) examined in the Affiliated Bao'an Hospital of Shenzhen between July 2016 and June 2017 were selected as the subjects. According to the inclusion and exclusion criteria, these patients were divided into three groups of 30 patients each: Control; hyperuricaemia; and gouty nephropathy groups. The control group included in the study underwent a standard health examination. Hyperuricaemia was considered when serum uric acid values were $>7 \mathrm{mg} / \mathrm{dl}$ for males (11). The diagnosis of gouty nephropathy is based on the diagnosis of primary gout (12), with a diagnosis of at least one of the following: Urinary protein $\geq 150 \mathrm{mg} / \mathrm{dl}$; urine white blood cells $>5 /$ high power field (HPF); urine red blood cells $>3 / \mathrm{HPF}$; serum creatinine $>115 \mu \mathrm{mol} / \mathrm{l}$; and blood uric acid/creatinine $>2.5$. Additionally, an ultrasound or ureterography revealing renal calculus or a shrunken kidney was also considered. All of the aforementioned cases excluded urinary tract infections and other diseases, including cancer. In addition, the exclusion criteria, were as follows: Female sex; age $<18$ years or $>70$ years; patients with secondary hyperuricaemia or stage 4-5 chronic kidney disease; acute hyperuricaemia; and the existence of acute renal function deterioration factors. Additionally, patients with hyperglycaemia, severe cardiovascular diseases, liver and kidney disease, lung disease, fractures, tumours, infectious and autoimmune diseases, and mental illness were excluded. Exceptions to these were diseases that may affect the NLRP3 inflammasome signalling pathways. Other exclusion criteria included the use of uric acid drugs outside the hospital or treatment with lipid-lowering drugs or anti-inflammatory and anti-oxidative drugs during the 4 weeks prior to admission.

Materials and reagents. Cell culture reagents including media, PBS and TRIzol ${ }^{\circledR}$ were obtained from Invitrogen; Thermo
Fisher Scientific, Inc. Methanol and acetonitrile were purchased from Merck $\mathrm{KGaA}$ and $\mathrm{NH}_{4} \mathrm{HCO}_{3}$ from Sigma-Aldrich; Merck KGaA. The Dynabeads ${ }^{\circledR}$ Untouched $^{\mathrm{TM}}$ Human Monocytes kit was purchased from Invitrogen; Thermo Fisher Scientific, Inc. The RevertAid First Strand cDNA Synthesis kit, and Applied Biosystems 7500 and qPCR equipment were purchased from Thermo Fisher Scientific, Inc. Antibodies against NLRP3, ASC and Caspase-1 (NLRP3, cat. no. sc-134306; Caspase-1, cat. no. sc-622; ASC, cat. no. sc-514414) were purchased from Santa Cruz Biotechnology, Inc. The BCA kit was purchased from Pierce; Thermo Fisher Scientific, Inc. The human IL-18 (cat. no. 70-EK1182) and IL-1 $\beta$ (cat. no. 70-EK101B2) ELISA kits were purchased from Hangzhou MultiSciences (Lianke) Biotech. UPLC was purchased from Waters Corporation and the Triple $\mathrm{TOF}^{\mathrm{TM}}$ 5600+ Mass Spectrometry system was obtained from AB SCIEX LLC.

Detection of organ function indicators. Sera and urine samples were obtained after $8 \mathrm{~h}$ of fasting. A $50 \mu \mathrm{l}$ sample of serum was collected from each patient, centrifuged at $500 \mathrm{xg}$ for $10 \mathrm{~min}$ at $4^{\circ} \mathrm{C}$, and the supernatant was collected and immediately stored at $-80^{\circ} \mathrm{C}$ until LC-MS analysis. A $15 \mathrm{ml}$ serum sample was collected and sent to Laboratory Services (Affiliated Bao'an Hospital of Shenzhen) for biochemical analysis. Urinary biochemical parameters were measured in the first urine-voiding sample of the day. Standard biochemical parameters performed included blood lipids, urine analysis, liver, renal and coagulation functions.

Isolation of peripheral blood mononuclear cells. Anti-coagulated blood was centrifuged at $1,600 \mathrm{x} g$ for $10 \mathrm{~min}$ at $4^{\circ} \mathrm{C}$, and the buffy coat was collected and stored at $-80^{\circ} \mathrm{C}$ for future use. Peripheral blood mononuclear cells were isolated from the lymphocyte lysate. Mononuclear cells were isolated by negative selection using magnetic beads from the Dynabeads ${ }^{\circledR}$ Untouched ${ }^{\mathrm{TM}}$ Human Monocytes kit according to the protocol of the manufacturer. The isolated mononuclear cell lysates were separated and $5 \mu \mathrm{l}$ was used for counting, and the number of monocytes used for RNA extraction and the cells used for the western blot analysis experiments were divided into 1:2 ratios. Then, $200 \mu 1$ TRIzol $^{\circledR}$ was added to mononuclear cells for RNA extraction and $\sim 50 \mu 1$ PBS was used for western blot analysis experiments.

Reverse transcription-quantitative polymerase chain reaction (RT-qPCR), western blot analysis and ELISA assays. TRIzol ${ }^{\circledR}$ (Invitrogen; Thermo Fisher Scientific, Inc.) was used to extract RNA from leukocytes (200,000-400,000 cells). Following the protocol of the manufacturer of the Revert Aid First Strand cDNA Synthesis kit (cat. no: K1622; Thermo Fisher Scientific, Inc.) and the TransStart ${ }^{\circledR}$ Tip Green qPCR SuperMix (2X) kit (cat. no. AQ141; TransGen Biotech Co., Ltd.), which contained the SYBR Green I fluorophore, the RNA content of NLRP3, ASC and caspase- 1 in the samples was detected. $\beta$-actin gene was used as the internal reference. The primer sequences are presented in Table I. PCR was conducted using the Applied Biosystems 7500 system (Applied Biosystems; Thermo Fisher Scientific, Inc.) with the following thermocycling conditions: Pre-denaturation at $95^{\circ} \mathrm{C}$ for $30 \mathrm{sec}$, followed by 40 cycles at $95^{\circ} \mathrm{C}$ for $5 \mathrm{sec}$ and $60^{\circ} \mathrm{C}$ for $30 \mathrm{sec}$; finally, the melting curve 
Table I. Primer sequences.

\begin{tabular}{lll}
\hline Group & \multicolumn{1}{c}{ Upstream } & \multicolumn{1}{c}{ Downstream } \\
\hline$\beta$-actin & 5'-AACCGCGAGAAGATGACCCAGAT-3' & 5'-GGATAGCACAGCCTGGATAGCA-3' \\
NLRP3 & 5'-ATGGGTTTACTGGAGTACCTTTC-3' & 5'-CTGTCTTCAATGCACTGGAATCTG-3' \\
ASC & 5'-GATGCTCTGTACGGGAAGGTC-3' & 5'-TCCAGTTCCAGGCTGGTGT-3' \\
Caspase-1 & 5'-GGAAGACTCATTGAACATATGCAAG-3' & 5'-CTTGTCAAAGTCACTCTTTCAGTG-3' \\
\hline
\end{tabular}

NLRP3, Nod-like receptor protein 3; ASC, apoptosis-associated speck like protein.

was generated (dissociation, $60^{\circ} \mathrm{C}$ at $30 \mathrm{sec}$ and $95^{\circ} \mathrm{C}$ at $15 \mathrm{sec}$ ) to test specificity of the primers and PCR reactions. Gene expression was calculated using the $2^{-\Delta \Delta C q}$ method (13).

For western blotting, cells were washed 3 times with PBS solution (Invitrogen; Thermo Fisher Scientific, Inc.) and lysed in ice-cold lysis buffer (cat. no. R0020; Beijing Solarbio Science \& Technology Co., Ltd.). Quantitative analysis of protein concentrations was performed according to the protocol of the bicinchoninic acid kit (cat. no. 23225; Thermo Fisher Scientific, Inc.). Protein samples $(10 \mu \mathrm{g})$ were added to SDS-PAGE gels $(8,10$ or 12\%) and electrophoresed at $100 \mathrm{~V}$. Gels were transferred to PVDF membranes (EMD Millipore), blocked with 5\% milk/TBS-1\% Tween [Sangon Biotech (Shanghai) Co., Ltd.] at room temperature for $1 \mathrm{~h}$. Primary antibodies [NLRP3, 1:300; Caspase-1, 1:300; ASC (all Santa Cruz Biotechnology, Inc.); GAPDH, 1:1,000 (cat. no. A01020-1; Abbkine, Inc.)] were diluted with $1 \%$ BSA/PBS-0.1\% Tween (PBST) [Sangon Biotech (Shanghai) Co., Ltd.], and membranes were incubated with them at $4^{\circ} \mathrm{C}$ overnight. Subsequently, the PVDF membranes were incubated with horseradish peroxidase-labeled secondary antibodies [goat anti-mouse (1:1,000; cat. no. A0216; Beyotime Institute of Biotechnology); goat anti-rabbit (1:10,000; cat. no. A21020-1; Abbkine, Inc.) diluted in 5\% milk/PBST at room temperature for $1 \mathrm{~h}$ with agitation. The PVDF membranes were then exposed to a luminescent reagent (cat. no. 32109; Thermo Fisher Scientific, Inc.) for 1.5-2.0 min and were observed with a gel imaging system (Gel Doc ${ }^{\mathrm{TM}} \mathrm{XR}+\mathrm{Gel}$ Documentation system; Bio-Rad Laboratories, Inc.). Concentrations of IL- $1 \beta$ and IL-18 in the plasma were measured using ELISA kits according to manufacturer's protocol.

Sample preparation prior to UPLC-MS. Serum samples were thawed at room temperature prior to analysis. Briefly, $50 \mu 1$ serum was prepared, and $200 \mu \mathrm{l}$ methanol containing the internal standard molecules was added, following which $180 \mu \mathrm{l}$ supernatant was freeze-dried. The lyophilized powder was re-dissolved in $80 \mu 1$ acetonitrile/water in a volume ratio of $1 / 4$ and vortexed for $30 \mathrm{sec}$. The supernatant was centrifuged at $500 \mathrm{x} \mathrm{g}$ for $10 \mathrm{~min}$ at $4^{\circ} \mathrm{C}$ and injected into the UPLC system for analysis. Concomitantly, in order to monitor the condition and stability of the UPLC instrument system, a blank control sample was injected prior to analysis of each sample.

Chromatography protocol. For LC-MS analysis, $5 \mu 1$ sample was injected. Chromatography was performed using a Waters BEH C8 column (100x2.1 mm; $1.7 \mu \mathrm{m}$; Waters Corporation) in positive ion mode. The column was maintained at $50^{\circ} \mathrm{C}$. The mobile phase consisted of $0.1 \%$ formic acid in water (A) and $0.1 \%$ formic acid in acetonitrile (B). With a flow rate of $0.35 \mathrm{ml} / \mathrm{min}$, the gradient condition of the mobile phase was as follows: The initial gradient was $10 \% \mathrm{~B}$ over $1 \mathrm{~min}$, then reaching $40 \%$ in $4 \mathrm{~min}$, and finally reaching $100 \%$ in $12 \mathrm{~min}$ and sustained for $5 \mathrm{~min}$. Subsequently, it was returned to the initial $10 \%$ in $22.1 \mathrm{~min}$ and maintained for $2.9 \mathrm{~min}$ for optimal column balance.

Chromatography was performed on an ACQUITY UPLC HSS T3 column (100 x $2.1 \mathrm{~mm}, 1.8 \mu \mathrm{m}$; Waters Corporation) in negative ion mode. The column was maintained at $50^{\circ} \mathrm{C}$. The mobile phase consisted of $0.1 \% 6.5 \mathrm{mM} \mathrm{NH}_{4} \mathrm{HCO}_{3}$ in water (A) and $95 \%$ methanol and $6.5 \mathrm{mM} \mathrm{NH}_{4} \mathrm{HCO}_{3}$ in water (B). With a flow rate of $0.35 \mathrm{ml} / \mathrm{min}$, the gradient condition of the mobile phase was as follows: The initial gradient was $0 \% \mathrm{~B}$ over $1 \mathrm{~min}$, reaching $40 \%$ in $2 \mathrm{~min}$, and finally reaching $100 \%$ in $13 \mathrm{~min}$ and sustained for $5 \mathrm{~min}$. Subsequently, it was returned to the initial $0 \%$ in $22.1 \mathrm{~min}$ and maintained for $2.9 \mathrm{~min}$ for optimal column balance. A mixture of internal standards was injected, and their times were used to correct retention time drifts due to different instruments and different experimental batches. The internal standards used for the positive and negative ion modes are summarized in Table II.

Mass spectrometry conditions. The pooled serum extract was analysed by a UPLC system coupled with an AB SCIEX Triple TOF $5600+$ System operating in negative and positive ion electrospray ionization modes. The scanning $\mathrm{m} / \mathrm{z}$ range was from 50 to 1,200 . Curtain gas, ion source gas 1 and ion source gas 2 were set at $0.241,0.276$, and $0.276 \mathrm{MPa}$, respectively. The following conditions were used: Curtain gas, 35 PSI; ion source gas 1, 50 PSI; ion source gas 2, 50 PSI; interface heater temperature, $500^{\circ} \mathrm{C}$. The cluster voltage and collision energy were, respectively, set at 100 and $10 \mathrm{~V}$ for the positive mode, and -100 and $-10 \mathrm{~V}$ for the negative mode. The sample was also analysed by IDA auto-MS ${ }^{2}$ mode with the collision energy voltage set at 20 and $40 \mathrm{eV}$ for positive mode, and -20 and $-40 \mathrm{~V}$ for negative mode.

Statistical analysis. Data were identified using Marker View software for peak identification and peak matching, and pattern recognition analysis was performed using SIMCA-P software (v 11.0; Sartorius Stedum Data Analytics). Principal component analysis (PCA) was applied. Heat map analysis was performed using the Multiple Experiment Viewer 4.5 software (mev.tm4.org). Potential biomarkers in the plasma 
Table II. Internal standards used for retention time calibration.

\begin{tabular}{llc}
\hline $\begin{array}{l}\text { Internal } \\
\text { standard }\end{array}$ & $\begin{array}{c}\text { Molecular } \\
\text { formula }\end{array}$ & $\begin{array}{c}\text { Concentration } \\
(\mu \mathrm{g} / \mathrm{ml})\end{array}$ \\
\hline Carnitine C2:0-d3 & $\mathrm{C}_{9} \mathrm{D}_{3} \mathrm{H}_{14} \mathrm{NO}_{4}$ & 0.16 \\
Carnitine C10:0-d3 & $\mathrm{C}_{17} \mathrm{D}_{3} \mathrm{H}_{30} \mathrm{NO}_{4}$ & 0.10 \\
Carnitine C16:0-d3 & $\mathrm{C}_{23} \mathrm{D}_{3} \mathrm{H}_{42} \mathrm{NO}_{4}$ & 0.15 \\
LPC 19:0 & $\mathrm{C}_{27} \mathrm{H}_{56} \mathrm{NO}_{7} \mathrm{P}$ & 0.75 \\
FFA C16:0-d3 & $\mathrm{C}_{16} \mathrm{H}_{32} \mathrm{O}_{2}$ & 2.50 \\
FFA C18:0-d3 & $\mathrm{C}_{18} \mathrm{H}_{36} \mathrm{O}_{2}$ & 2.50 \\
CA-d4 & $\mathrm{C}_{24} \mathrm{D}_{4} \mathrm{H}_{36} \mathrm{O}_{5}$ & 1.85 \\
CDCA-d4 & $\mathrm{C}_{24} \mathrm{D}_{4} \mathrm{H}_{36} \mathrm{O}_{4}$ & 1.49 \\
leu-d3 & $\mathrm{C}_{6} \mathrm{H}_{13} \mathrm{NO}_{2}$ & 5.00 \\
Phe-d5 & $\mathrm{C}_{9} \mathrm{D}_{5} \mathrm{H}_{6} \mathrm{NO}_{2}$ & 3.61 \\
Trp-d5 & $\mathrm{C}_{11} \mathrm{D}_{5} \mathrm{H}_{7} \mathrm{~N}_{2} \mathrm{O}_{2}$ & 4.25 \\
\hline
\end{tabular}

were identified based on the in-house database and the Human Metabolome Database (http://www.hmdb.ca/). The in-house LC-MS database (14) was established under standard operation procedure conditions using available metabolite standards and previously identified metabolites. Data are presented as the mean \pm standard deviation. A one-way analysis of variance was used to compare the means of multiple groups followed by the Bonferroni test. Student's t-test was used to compare the mean values between the hyperuricaemia and gouty nephropathy groups. Metabolites that were significantly different between the two groups, as determined by Student's t-test, were considered to be the biomarkers responsible for the differentiation of hyperuricaemia from nephropathy group. $\mathrm{P}<0.05$ were considered to be statistically significant. Statistical analyses were performed using SPSS 17.0 software (SPSS, Inc.).

\section{Results}

General observations. As demonstrated in Tables III and IV, no significant differences in terms of age, body mass index and mean arterial pressure were observed between the control, hyperuricaemia and nephropathy groups. Serum uric acid and creatinine are important metabolites in hyperuricaemia. The levels of serum creatinine and blood urea nitrogen are the most commonly used indicators of renal function. Urine leukocyte, urine erythrocyte and urine protein levels were used to indicate the progression of gouty nephropathy. A marked increase in uric acid and creatinine levels was observed in the hyperuricaemia and gouty nephropathy groups compared with the control group $(\mathrm{P}<0.01)$. Additionally, the levels of uric acid, creatinine, blood urea nitrogen, urine leukocyte, urine erythrocyte and urine protein were increased in the gouty nephropathy group when compared with the hyperuricaemia group $(\mathrm{P}<0.05)$. These results demonstrated that the kidney had been damaged in the progression from hyperuricaemia to gouty nephropathy.

Fasting blood glucose and blood lipids levels indicate the level of blood glucose and lipid metabolism in the body, respectively. In the present study, the fasting blood glucose levels in the hyperuricemia and gouty nephropathy groups were slightly increased compared with that in the control group, which was considered to be the result of the small sample size. None of the patients selected in the present study had diabetes. The indicators of blood lipids include total cholesterol, total triglycerides, high density lipoprotein and low-density lipoprotein levels. Compared with the control group, the hyperuricaemia and gouty nephropathy groups exhibited a significant increase in fasting blood glucose levels $(\mathrm{P}<0.01)$ : However, there was no significance between the hyperuricaemia and gouty nephropathy groups. Compared with the control and hyperuricaemia groups, the levels of total triglycerides were significantly increased in the gouty nephropathy group $(\mathrm{P}<0.01)$. These results suggested that lipid disorders may serve a role in the progression from hyperuricaemia to gouty nephropathy.

Peripheral blood mononuclear cells. The peripheral blood mononuclear cells were isolated for analysis. The Trypan Blue staining test confirmed that $>95 \%$ of cells were living. The cell concentration was adjusted to $5 \times 10^{5} / \mathrm{ml}$. Cell counts are presented in Table V.

mRNA and protein expression of NLRP3, ASC and caspase-1 in peripheral blood mononuclear cells and ELISA analyses of plasma IL-1 $\beta$ and IL-18 levels. Compared with the control group, the expression levels of NLRP3, ASC and caspase-1 mRNA, and ASC and caspase-1 protein in peripheral blood mononuclear cells were increased in the hyperuricaemia and gouty nephropathy groups $(\mathrm{P}<0.05)$. Additionally, the levels of IL-1 $\beta$ and IL-18 in plasma were increased $(\mathrm{P}<0.01)$. Compared with the hyperuricaemia group, the gouty nephropathy group exhibited increased NLRP3 and ASC mRNA expression levels, and ASC and caspase-1 protein expression levels, and IL-1 $\beta$ and IL-18 plasma levels ( $\mathrm{P}<0.05$; Table VI; Fig. 1). These data suggested that the expression levels of NLRP3 protein were consistent with the pattern of its corresponding mRNA expression level, exhibiting an increase in expression in the gouty nephropathy group when compared with the control and hyperuricaemia groups. This result suggests that NLRP3 may serve a regulatory role in the inflammatory process of gouty nephropathy. In particular, the notable increase in the expression levels of the inflammasome factors IL-1 $\beta$ and IL-18 indicated that the NLRP3 inflammasome was closely associated with gouty nephropathy.

Plasma metabolomics analysis. Fig. 2 demonstrates the base peak intensity chromatograms of plasma metabolic profiles analysed using UPLC-QTOF/MS in the positive and negative ion modes. According to the score plots in the positive and negative ion modes (Fig. 3A and B), the clustering patterns of the control and hyperuricaemia groups were observed to be distinct, but with partial overlap. Concomitantly, the clustering pattern of the gouty nephropathy group deviated from those of the control and hyperuricaemia groups. The profile demonstrated a clear intergroup separation in plasma metabolites in the gouty nephropathy group from the control and hyperuricaemia groups.

In the S-plot, each point represents a metabolite. The two ends of the S-shaped curve represent the ions with highest confidence intervals and levels of contribution. As indicated in 
Table III. Clinical and demographic summary.

Groups

\begin{tabular}{lccc}
\cline { 2 - 3 } Characteristics & Healthy control $(\mathrm{n}=30)$ & Hyperuricemia $(\mathrm{n}=30)$ & Gouty nephropathy $(\mathrm{n}=30)$ \\
\hline Age, years & $47.00 \pm 10.19$ & $43.27 \pm 12.91$ & $44.32 \pm 11.51$ \\
BMI, $\mathrm{kg} / \mathrm{m}^{2}$ & $23.95 \pm 1.51$ & $24.67 \pm 3.24$ & $23.70 \pm 2.58$ \\
MAP, $\mathrm{mmHg}$ & $88.57 \pm 7.08$ & $88.00 \pm 7.21$ & $89.94 \pm 6.33$ \\
FBG, $\mathrm{mmol} / \mathrm{l}$ & $4.73 \pm 0.45$ & $5.17 \pm 0.70^{\mathrm{a}}$ & $4.77 \pm 0.39^{\mathrm{b}}$ \\
\hline
\end{tabular}

Data are presented as the mean \pm standard deviation. BMI, body mass index; MAP, mean arterial pressure; FBG, fasting blood glucose. ${ }^{\mathrm{a} P}<0.01$ vs. healthy control group; ${ }^{b} \mathrm{P}<0.01 \mathrm{vs}$. hyperuricemia group.

Table IV. Organ function indicators of enrolled patients.

\section{Groups}

\begin{tabular}{lccc} 
Characteristics & Healthy control $(\mathrm{n}=30)$ & Hyperuricemia $(\mathrm{n}=30)$ & Gouty nephropathy $(\mathrm{n}=30)$ \\
\cline { 2 - 4 } $\mathrm{UA}, \mathrm{mmol} / \mathrm{l}$ & $204.30 \pm 61.43$ & $513.13 \pm 120.88^{\mathrm{a}}$ & $550.06 \pm 82.95^{\mathrm{a}, \mathrm{b}}$ \\
$\mathrm{Cr}, \mu \mathrm{mol} / \mathrm{l}$ & $35.72 \pm 9.36$ & $65.63 \pm 26.32^{\mathrm{a}}$ & $72.65 \pm 22.60^{\mathrm{a}, \mathrm{b}}$ \\
$\mathrm{BUN}, \mathrm{mmol} / \mathrm{l}$ & $4.34 \pm 1.17$ & $4.65 \pm 1.55$ & $5.72 \pm 1.74^{\mathrm{a}, \mathrm{b}}$ \\
$\mathrm{TC}, \mathrm{mmol} / \mathrm{l}$ & $4.35 \pm 1.25$ & $5.21 \pm 1.10$ & $4.94 \pm 1.29$ \\
$\mathrm{TG}, \mathrm{mmol} / \mathrm{l}$ & $0.95 \pm 0.48$ & $1.23 \pm 0.54^{\mathrm{c}}$ & $2.07 \pm 1.71^{\mathrm{a}, \mathrm{d}}$ \\
$\mathrm{HDL}, \mathrm{mmol} / \mathrm{l}$ & $1.52 \pm 0.46$ & $1.41 \pm 0.49$ & $1.33 \pm 0.47$ \\
LDL, mmol/l & $2.32 \pm 0.79$ & $2.76 \pm 1.08$ & $3.30 \pm 0.85$ \\
Urine leukocyte, $/ \mathrm{HP}$ & $1.17 \pm 1.15$ & $1.41 \pm 1.74$ & $4.33 \pm 8.88^{\mathrm{b}, \mathrm{c}}$ \\
Urine erythrocyte, $/ \mathrm{HP}$ & $0.66 \pm 0.90$ & $1.97 \pm 1.80$ & $28.07 \pm 52.06^{\mathrm{a}, \mathrm{d}}$ \\
Urine protein & $\mathrm{ND}$ & $\mathrm{ND}$ & +
\end{tabular}

Data are presented as the mean \pm standard deviation. UA, uric acid; Cr, creatinine; BUN, blood urea nitrogen; TC, total cholesterol; TG, total triglycerides; HDL, high density lipoprotein; LDL, low density lipoprotein; ND, data not determined. + , proteinuria. ${ }^{a} \mathrm{P}<0.01 \mathrm{vs}$. healthy control group; ${ }^{\mathrm{b}} \mathrm{P}<0.05$ vs. hyperuricemia group; ${ }^{\mathrm{c}} \mathrm{P}<0.05 \mathrm{vs}$. healthy control group; ${ }^{\mathrm{d}} \mathrm{P}<0.01$ vs. hyperuricemia group.

Table V. Peripheral blood mononuclear cells count.

\begin{tabular}{lll}
\hline Group & $\mathrm{N}$ & Count $\left(10^{5}\right)$ \\
\hline Control & 30 & $39.760 \pm 21.453$ \\
Hyperuricemia & 30 & $43.803 \pm 16.393$ \\
Gouty nephropathy & 30 & $30.100 \pm 13.365$ \\
\hline
\end{tabular}

Fig. 3C and D, the variables far from the centre of the plot were considered to be the biomarkers, based on the results between the hyperuricaemia and gouty nephropathy groups from the Student's t-test $(\mathrm{P}<0.05)$.

A heat map was generated based on the analysis of the identified potential biomarkers between the hyperuricaemia and the gouty nephropathy groups. As shown in Fig. 4, a red signal indicated an increase in metabolite level while the blue signals indicated a decrease in metabolite level; these signals were used to visualize the trend changes in the metabolites between the groups.
Identification of potential biomarkers. These metabolites were considered to be potential biomarkers based on the Student's $\mathrm{t}$-test results $(\mathrm{P}<0.05)$. Based on the combined information on retention time and accurate mass MS1 and MS2 spectra, the metabolomics analysis data were used to batch retrieve the in-house database. The results with a score value $>0.6$ were retained. Potential biomarkers in the plasma were identified based on the in-house database and the Human Metabolome Database (http://www.hmdb.ca/).

In the present study, 46 potential biomarkers were identified, as described in Table VII. Compared with the hyperuricaemia group, the levels of lysophosphatidylcholine (LPC)20:5, LPC15:0, LPC18:2, LPC20:4, LPC22:6, LPC16:1, LPC22:5, LPC18:0, lysophosphatidylethanolamine (LPE)16:0, LPE18:2, phosphatidyl ethanolamine (PE)38:6, PE38:7, PE34:3, phosphatidylcholine (PC)32:3, PC32:1, PC34:3, PC38:5, FA11:0, FA14:1, FA18:4, FA16:2, FA18:3, FA18:2, FA20:4, FA20:0, FA22:0, FA24:0, sphingomyelin (SM)32:1, SM34:1, carnitine C10:1, carnitine C16:1, carnitine C14:1, proline, lactic acid, uric acid, indoxyl sulphate, tryptophan, ursodeoxycholic acid (UDCA), tauroursodeoxycholic acid 
Table VI. mRNA and protein expression levels of NLRP3, ASC and caspase-1 in peripheral blood mononuclear cells and ELISA analyses for plasma IL-1 $\beta$ and IL-18 levels.

\section{Groups}

\begin{tabular}{lccc}
\cline { 2 - 3 } Indicators & Control $(\mathrm{n}=30)$ & Hyperuricemia $(\mathrm{n}=30)$ & Gouty nephropathy $(\mathrm{n}=30)$ \\
\hline NLRP3 mRNA & $23.91 \pm 1.28$ & $26.11 \pm 1.81^{\mathrm{a}}$ & $27.22 \pm 1.84^{\mathrm{a}, \mathrm{b}}$ \\
ASC mRNA & $24.81 \pm 1.56$ & $27.90 \pm 3.09^{\mathrm{a}}$ & $33.12 \pm 3.14^{\mathrm{a}, \mathrm{b}}$ \\
caspase-1 mRNA & $26.22 \pm 1.57$ & $29.16 \pm 2.71^{\mathrm{a}}$ & $29.04 \pm 2.32^{\mathrm{a}}$ \\
NLRP3/GAPDH & $0.45 \pm 0.21$ & $0.47 \pm 0.16^{\mathrm{c}}$ & $0.54 \pm 0.18^{\mathrm{c}}$ \\
ASC/GAPDH & $0.27 \pm 0.11$ & $0.41 \pm 0.19^{\mathrm{c}}$ & $0.52 \pm 0.18^{\mathrm{a}, \mathrm{d}}$ \\
Caspase-1/GAPDH & $0.51 \pm 0.15$ & $0.62 \pm 0.15^{\mathrm{a}}$ & $0.72 \pm 0.14^{\mathrm{c}, \mathrm{d}}$ \\
IL-1 $\beta$ (pg/ml) & $31.59 \pm 16.57$ & $49.92 \pm 16.05^{\mathrm{a}}$ & $81.49 \pm 25.93^{\mathrm{a}, \mathrm{b}}$ \\
IL-18 (pg/ml) & $312.30 \pm 93.54$ & $645.43 \pm 314.79^{\mathrm{a}}$ & $930.72 \pm 511.65^{\mathrm{a}, \mathrm{b}}$ \\
\hline
\end{tabular}

Values are means \pm SD. NLRP3, Nod-like receptor protein 3; ASC, apoptosis-associated speck like protein; IL-1 $\beta$, interleukin-1 $\beta$; IL-18, interleukin- 18 . ${ }^{\mathrm{a}} \mathrm{P}<0.01$ vs. healthy control; ${ }^{\mathrm{b}} \mathrm{P}<0.01$ vs. hyperuricemia; ${ }^{\mathrm{c}} \mathrm{P}<0.05$ vs. healthy control; ${ }^{\mathrm{d}} \mathrm{P}<0.05$ vs. hyperuricemia.

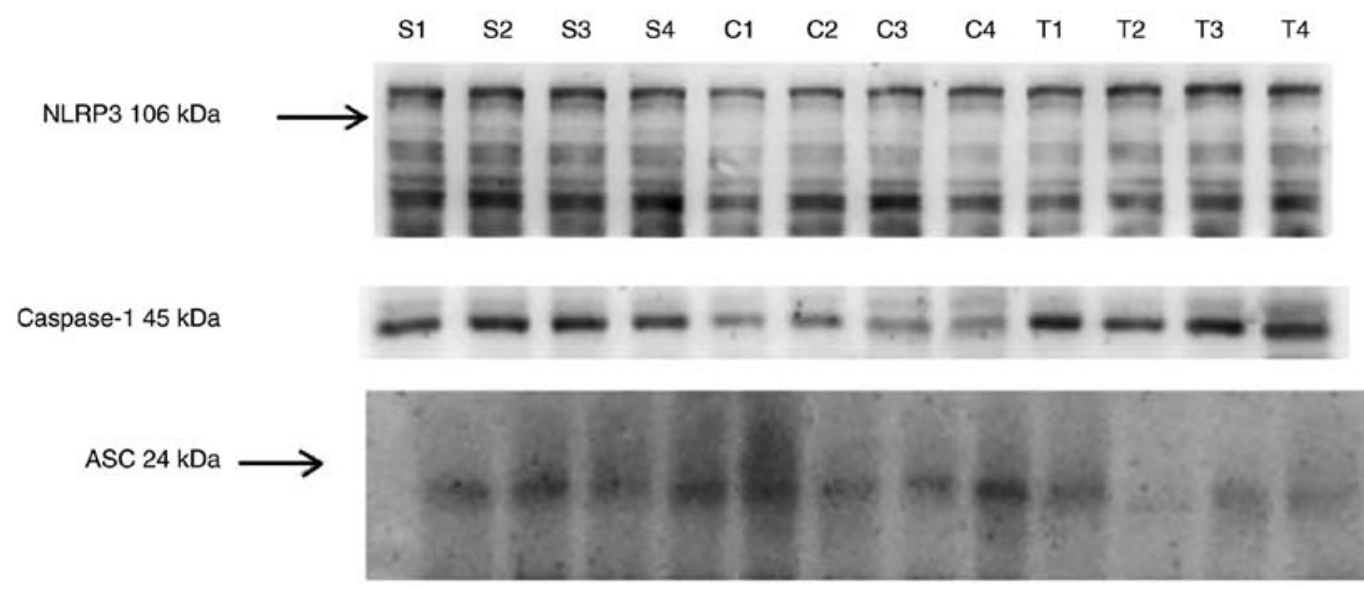

GAPDH 36 kDa

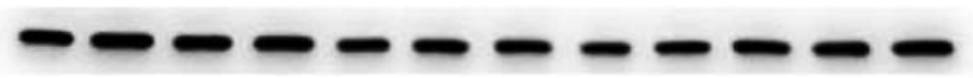

Figure 1. Expression of NLRP3, ASC and caspase-1 proteins in peripheral blood mononuclear cells. NLRP3, NOD-like receptor protein 3; ASC, apoptosis-associated speck like protein; C, control group; T, hyperuricaemia group; S, gouty nephropathy group.

(TDCA), chenodeoxycholic acid (CDCA) and p-cresol glucuronide were significantly increased in the gouty nephropathy group. However, the levels of LPC14:0, LPC16:0, PC33:2, PC32:0 and phenylalanine were significantly decreased in the gouty nephropathy group. The majority of these metabolites are involved in lipid metabolism (15).

\section{Discussion}

Long-term increases in uric acid levels in the body will lead to the deposition of urate crystals in the kidney, resulting in gouty nephropathy. The damage caused by uric acid is not only limited to the obstruction caused by monosodium urate (MSU) but also, more significantly, to the inflammatory response initiated by MSU crystals. Uric acid crystals have been demonstrated to trigger IL-1 $\beta$-mediated inflammation via activation of the NLRP3 inflammasome, a multi-molecular complex whose activation has been demonstrated to be central to a number of pathological inflammatory conditions (16). The hyperactivity of this complex of proteins underlies several human diseases, including diabetic nephropathy (17), atherosclerosis (18), non-alcoholic steatohepatitis (19) and ischaemia-reperfusion injury (20). The NLRP3 inflammasome potently modulates innate immune function by regulating the maturation and secretion of pro-inflammatory cytokines, including IL-1 $\beta$ and IL-18. Renewed interest in uric acid has been generated by observations indicating that MSU released by tissue or cell injury may activate the NLRP3 inflammasome and promote inflammatory responses (21). Uric acid, in its soluble form, is responsible for increasing IL-1 $\beta$ production in a NLRP3-dependent manner and is associated with the kidney damage (21).

In the present study, compared with the control and hyperuricaemia groups, the increased levels of creatinine and uric 
A IDA dependent sum from $q 7$.wiff(sample)-q7

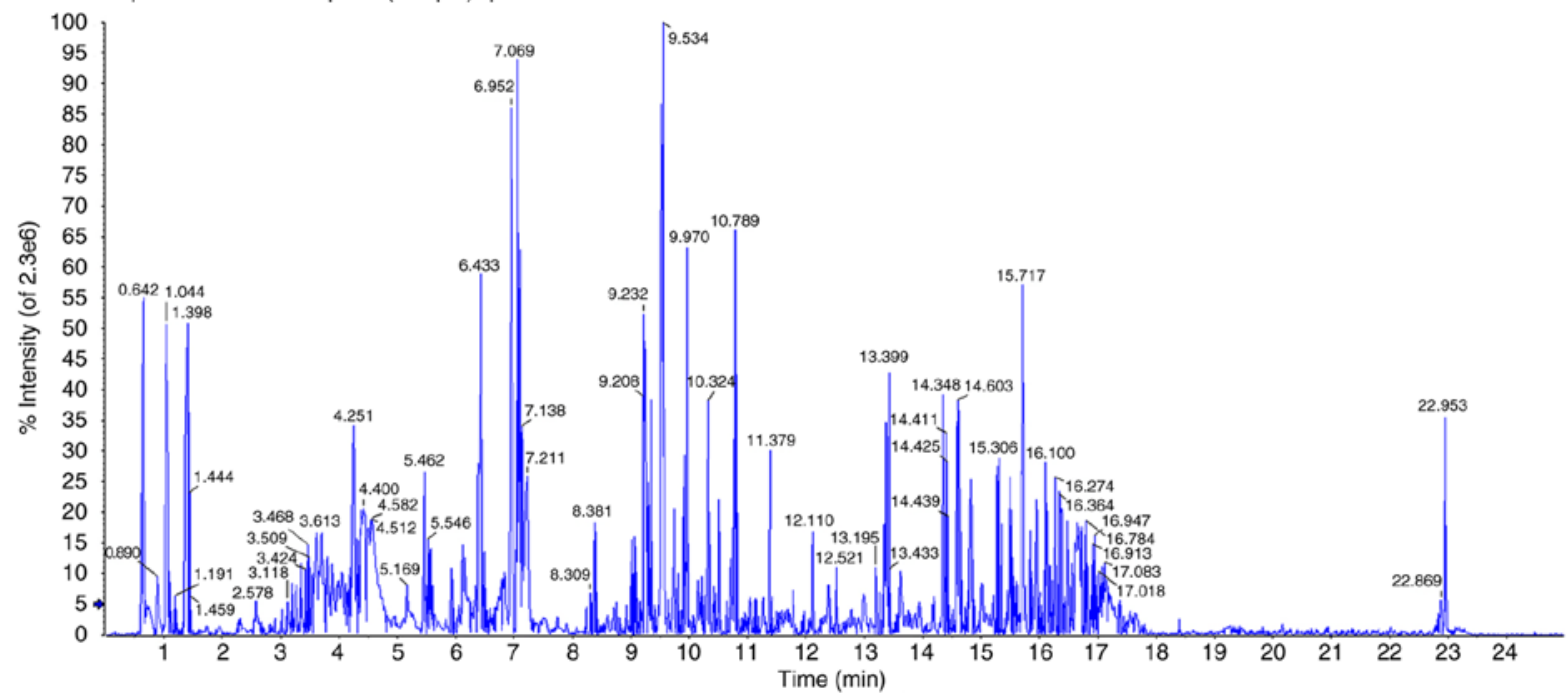

B IDA dependent sum from q8.wiff(sample)-q8

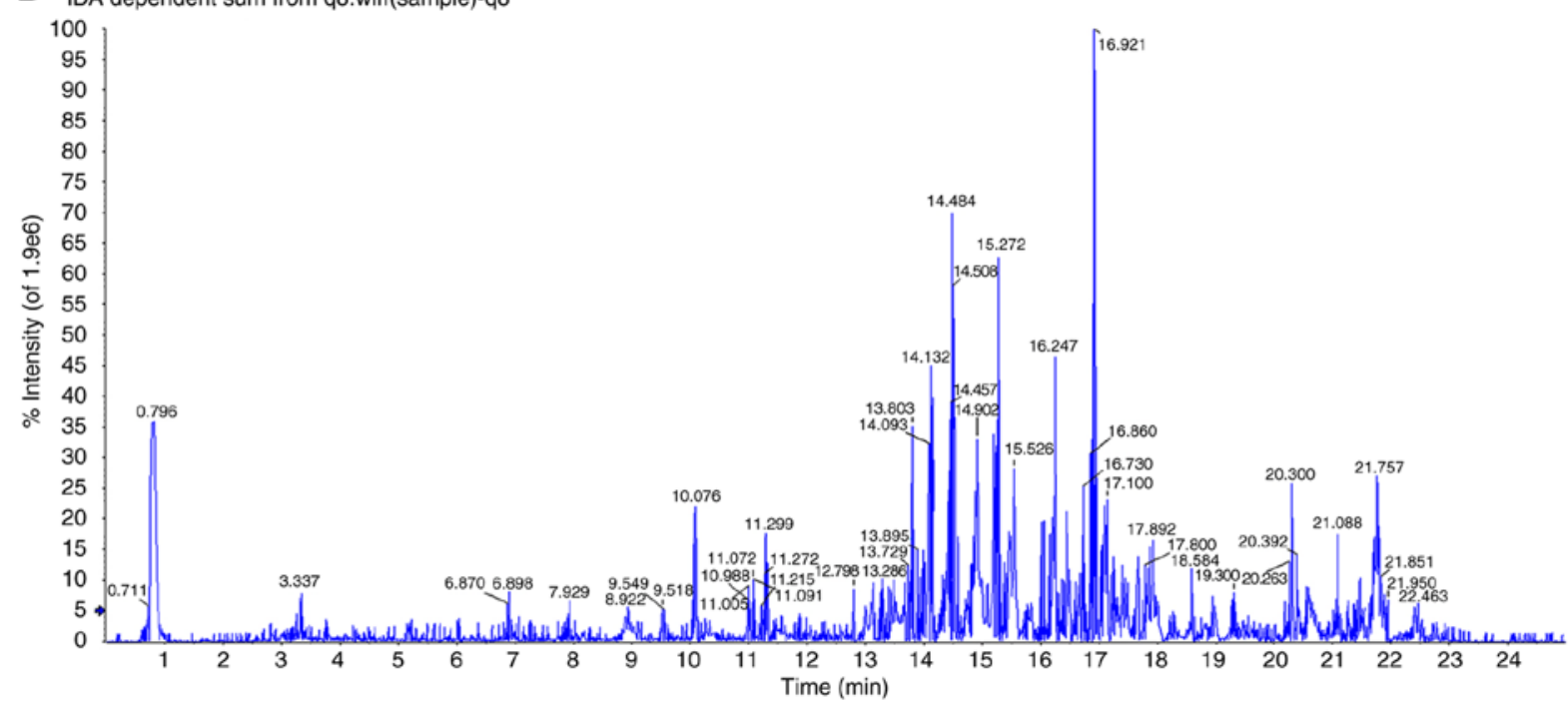

Figure 2. Base peak intensity chromatograms of plasma metabolic profiles of a patient based on ultra-performance liquid chromatography coupled with quadrupole time-of-flight mass spectrometry analysis in the (A) positive and (B) negative modes.

acid in the gouty nephropathy group indicated renal damage caused by uric acid. Most importantly, compared with the control group, the increased expression levels of NLRP3 inflammasome mRNA and protein in the hyperuricaemia and gouty nephropathy groups suggested that soluble uric acid upregulated expression of the NLRP3 inflammasome. Additionally, the increased levels of caspase- 1 protein, IL-1 $\beta$ and IL-18 in the hyperuricaemia and gouty nephropathy groups indicated that soluble uric acid caused the production of active caspase- 1 that cleaves pro-IL1 $\beta$ to the secreted form of IL-1 $\beta$. Compared with the hyperuricaemia group, the expression levels of NLRP3 inflammasome mRNA and protein, downstream inflammatory factors and IL-1 $\beta$ and IL-18 levels were increased in the gouty nephropathy group, which indirectly indicated that the NLRP3 inflammasome served a pivotal role in the progression of gouty nephropathy. The events leading to the activation of the NLRP3 inflammasome involve reactive oxygen species (ROS) (22), lysosomal rupture (23) and mitochondrial damage (24). As shown in Fig. 5, urate crystals may stimulate cells to produce ROS (25) or cause lysosomes to break down and release cathepsin B (26), and this stimulation of ROS production induces cells to release ATP, triggering a calcium wave transport mechanism (27) or a potassium ion outflow mechanism leading to mitochondrial damage, activating the NLRP3 inflammasome (28). It has also been suggested that uric acid may activate the NLRP3 inflammasome and contribute to the development of gouty nephropathy. In the present study, the measurement of disease severity considered objective indicators including renal function as the evaluation criteria when selecting the subjects. In future studies, the duration of the disease should be included in the analysis.

In the present study, metabolomics analysis provided metabolic information and information concerning the pathophysiology of biological events for determining the occurrence of changes in the target organ and the role of different sites and biomarkers (29-31). A total of 46 metabolites were considered as potential biomarkers in plasma, due to their down- or upregulation: The levels of 2 PC, 2 LPC and phenylalanine were downregulated, and the levels of 8 LPC, 2 LPE, 4 PC, 

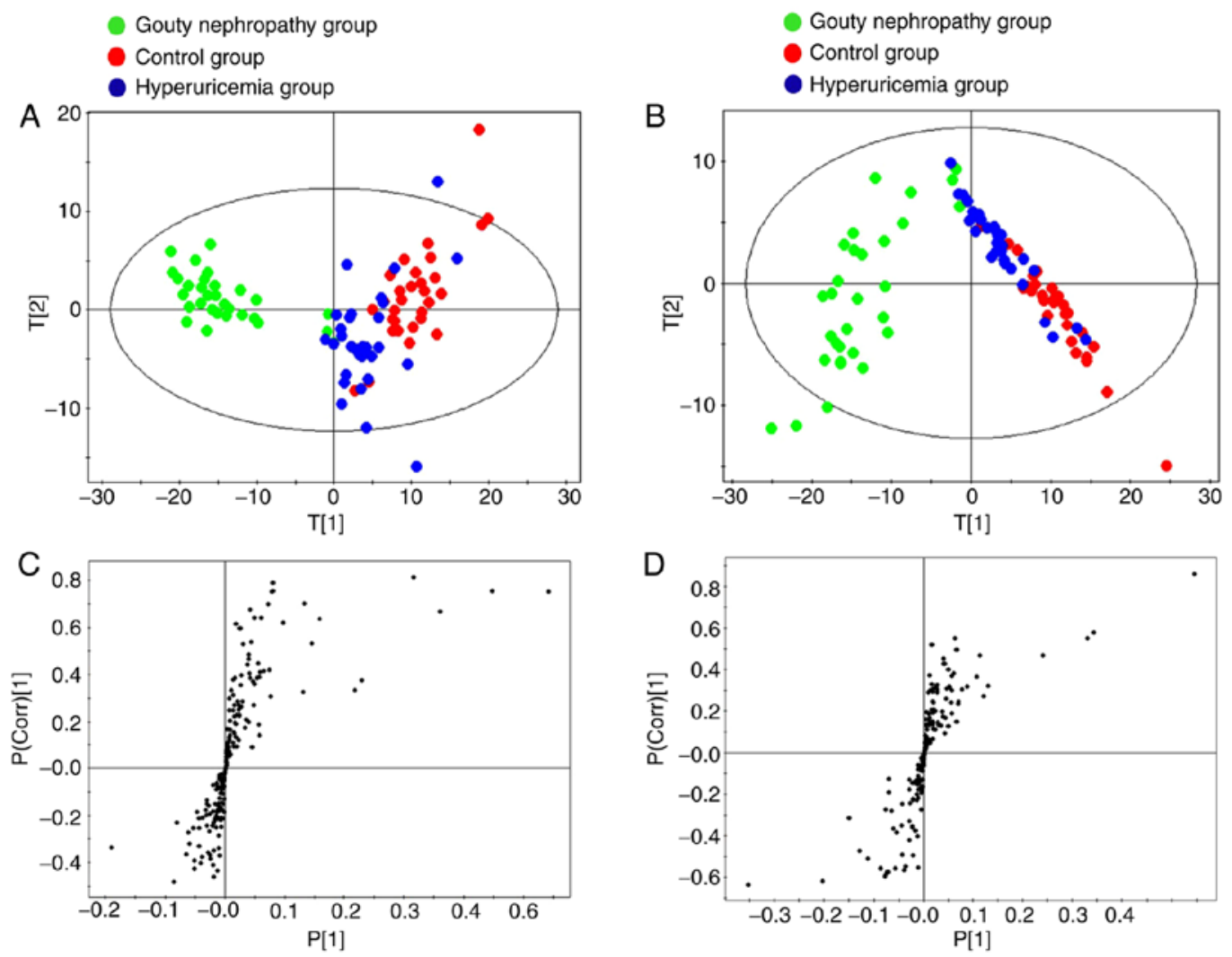

Figure 3. PLS-DA score plot and S-plot of analysis from plasma samples in the positive and negative modes. Red indicates the control group, blue indicates the hyperuricaemia group and green indicates the gouty nephropathy group. (A) The PLS-DA scores in the positive mode. (B) The PLS-DA scores in the negative mode. (C) S-plot in the positive mode. (D) S-plot in the negative mode.

3 PE, 10 FAs, 2 SM, 3 carnitines, lactic acid, uric acid, proline, indoxyl sulphate, tryptophan, p-cresol glucuronide, UDCA, TDCA and CDCA were upregulated in the gouty nephropathy group compared with the hyperuricaemia group. Among these 46 metabolites, significant changes in amino acid, glucose and lipid metabolism, and in bile acid biosynthesis were observed; however, the majority of the alterations involved lipid metabolism. Through analysis of all the metabolic pathways involved, a lipid metabolic network of the potential biomarkers and their alterations in gouty nephropathy modulation was constructed and is shown in Fig. 6. LPC and LPE are the fundamental components of cellular membranes and mediate signal transduction, and are formed by the hydrolysis of PC and PE by the enzyme phospholipase A2 (PLA2) $(15,32)$. PLA2 catalyses the decomposition of phospholipids to increase the production and accumulation of free FAs $(33,34)$. Subsequently, FAs release large amounts of ATP by $\beta$-oxidation (35). In the present study, the increased PC, LPC and LPE levels suggested the enhancement of PLA2 activity. Compared with the hyperuricaemia group, increased levels of carnitines and FAs in the gouty nephropathy group were detected in the plasma and indicated an increase in FA $\beta$-oxidation. These data suggested that gouty nephropathy was closely associated with lipid metabolism.

The mechanism of augmented uric acid production with lipid metabolism remains unknown. One explanation may be associated with the activity of PLA2. Lysophospholipids are generated by PLA 2 and are important in cell signalling and membrane biology. With the development of gouty nephropathy, PLA2 is activated, which accelerated the decomposition of phospholipids. The FAs released by PLA2, including arachidonic acid, have been demonstrated to function as sources of energy, signalling molecules and potent mediators of inflammation (36). PLA2 enzymatic activity has been associated with inflammatory conditions and, inhibitors of the PLA2 enzyme have been studied for their potential in decreasing pathologic inflammation (37). A previous study suggested that members of the Ginkgo phylum may decrease uric acid via adjustment of the level of LPCs by decreasing the activity of PLA2 (38). The identification of these endogenous metabolites provides an improved understanding of changes in phospholipid metabolism in gouty nephropathy.

A second mechanism may be associated with $\beta$-oxidation. During triglyceride synthesis, there is an increased requirement for NADPH and the synthesis of FAs in the liver, which is associated with the de novo synthesis of purines, thereby increasing the rate of uric acid production. The free FA produced by lipolysis is metabolized through $\beta$-oxidation with increased production of NADPH, which is additionally metabolized to uric acid, resulting in hyperuricaemia (39). In the $\beta$-oxidation process, increased free FAs enhance the levels of acetyl-coenzyme A, which competes with $\alpha$-ketoglutarate for entry into the Krebs cycle. Decreased metabolism of $\alpha$-ketoglutarate leads to its accumulation, in turn inhibiting of the catabolism of glutamine by the mass-law effect and effectively decreasing ammonia synthesis, thereby leading to lower urinary $\mathrm{pH}$ levels and uric acid deposition (40).

In the present study, lipid metabolism was also associated with the NLRP3 inflammasome in gouty nephropathy. Uric 


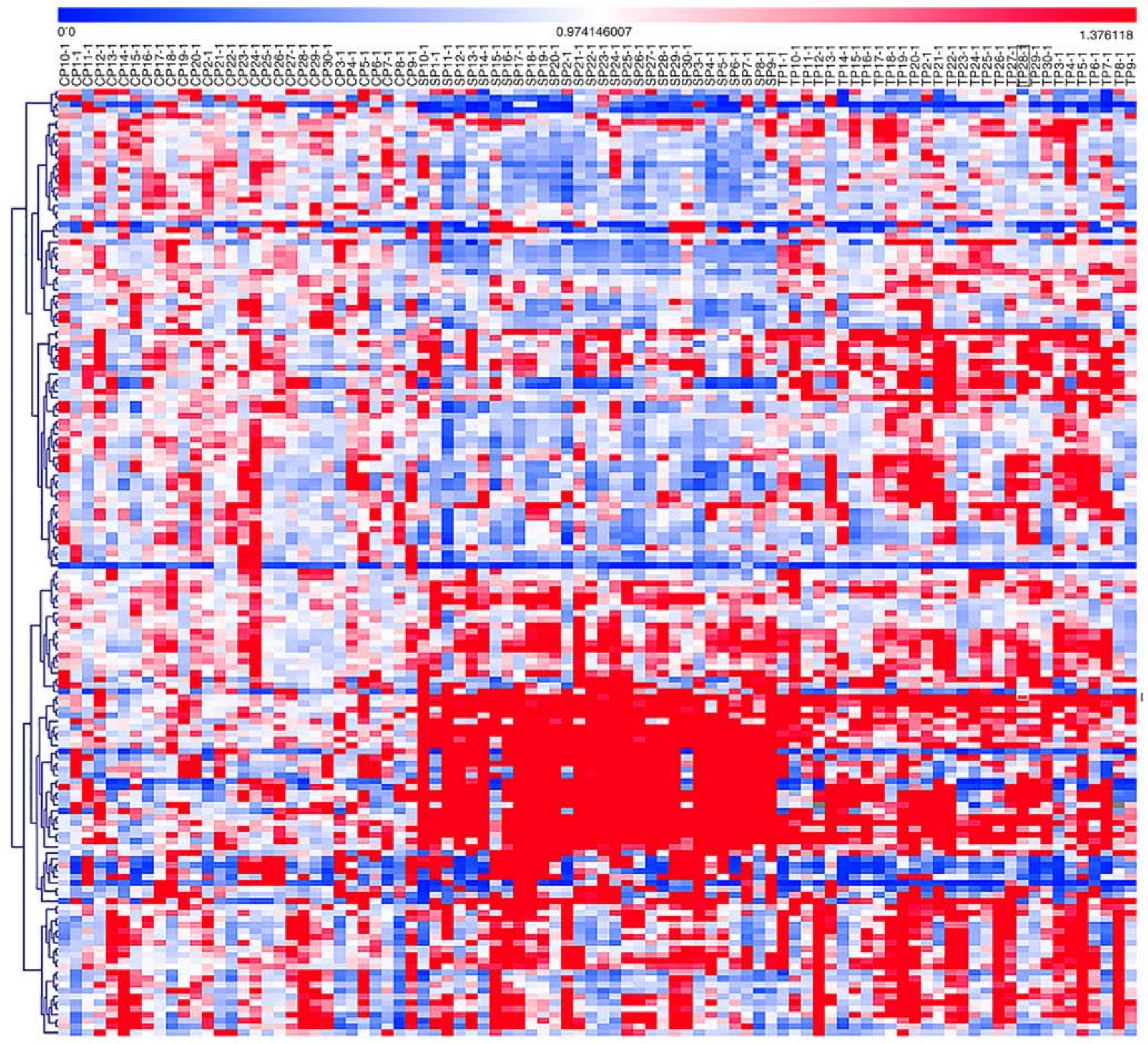

Figure 4. Heatmap of differential metabolites between the hyperuricaemia and gouty nephropathy groups. Red signals represent upregulation, and blue signals represent downregulation. The y-axis represents metabolites, the $\mathrm{x}$-axis represents samples.

acid has been demonstrated to increase triglyceride accumulation in cultured liver cells, and the mechanism was suggested to be mediated by intracellular and mitochondrial oxidative stress. More importantly, mitochondrial damage will not only release mitochondrial (mt)DNA, but also ROS and certain lipid substances, into the cytoplasm. There is evidence to suggest that the release of mtDNA and cardiolipin into the cytoplasm promoted the activation of the NLRP3 inflammasome (41). The NLRP3 inflammasome was first demonstrated to be activated by cholesterol crystals, and previous studies have shown that the NLRP3 inflammasome may also be activated by oxidized low-density lipoprotein or high glucose levels (42-45). The increased levels of the NLRP3 inflammasome and lipids, in particular the LPC, LPE, PC and FAs, demonstrated in the gouty nephropathy group in the present study suggested that lipids may mediate the progression of gouty nephropathy through the activity of PLA2 $\beta$-oxidation and activation of the NLRP3 inflammasome; however, these results require further validation.
Hyperuricaemia has been associated with hypertension, diabetes mellitus and metabolic syndrome, and the volume of evidence suggesting that fructose-induced hyperuricaemia serves a contributory role is increasing (46). Animal experiments have indicated that high fructose-induced hyperuricaemia is associated with hypertension, hypertriglyceridemia, hyperinsulinemia, glomerular hypertension, renal cortical arteriolar systole and renal anterior artery disease (47). In addition, elevated blood glucose levels may activate the NLRP3 inflammasome, induce inflammatory responses, increase IL- $1 \beta$ secretion and cause tissue damage (48). The NLRP3 inflammasome is crucial to the development of type 2 diabetes induced by glucose metabolism disorders (49). In the present study, compared with the control group, the hyperuricaemia and gouty nephropathy groups exhibited significant increases in fasting blood glucose levels $(\mathrm{P}<0.01)$, with a corresponding increase in the expression levels of the NLRP3 inflammasome components, 
Table VII. Biomarkers identified in plasma.

\begin{tabular}{|c|c|c|c|c|c|c|c|}
\hline No & $\mathrm{t}_{\mathrm{R}}(\min )$ & $\mathrm{m} / \mathrm{z}$ & Formula & Metabolite identification & Ratio & Regulation & P-value \\
\hline 1 & 8.28 & 468.309 & $\mathrm{C}_{22} \mathrm{H}_{46} \mathrm{NO}_{7} \mathrm{P}$ & LPC 14:0 & 0.74 & Down & 0.01 \\
\hline 2 & 8.49 & 542.3209 & $\mathrm{C}_{28} \mathrm{H}_{48} \mathrm{NO}_{7} \mathrm{P}$ & LPC 20:5 & 14.8 & $\mathrm{Up}$ & 0.01 \\
\hline 3 & 8.64 & 482.3239 & $\mathrm{C}_{23} \mathrm{H}_{48} \mathrm{NO}_{7} \mathrm{P}$ & LPC 15:0 & 2.39 & $\mathrm{Up}$ & 0.01 \\
\hline 4 & 9.201 & 520.3365 & $\mathrm{C}_{26} \mathrm{H}_{50} \mathrm{NO}_{7} \mathrm{P}$ & LPC 18:2 & 1.87 & $\mathrm{Up}$ & 0.01 \\
\hline 5 & 9.29 & 544.3395 & $\mathrm{C}_{28} \mathrm{H}_{50} \mathrm{NO}_{7} \mathrm{P}$ & LPC 20:4 & 13.3 & Up & 0.01 \\
\hline 6 & 9.31 & 568.3394 & $\mathrm{C}_{30} \mathrm{H}_{50} \mathrm{NO}_{7} \mathrm{P}$ & LPC 22:6 & 4.93 & Up & 0.01 \\
\hline 7 & 9.5 & 496.3391 & $\mathrm{C}_{24} \mathrm{H}_{50} \mathrm{NO}_{7} \mathrm{P}$ & LPC 16:0 & 0.15 & Down & 0.01 \\
\hline 8 & 9.88 & 480.342 & $\mathrm{C}_{24} \mathrm{H}_{48} \mathrm{NO}_{7} \mathrm{P}$ & LPC 16:1 & 5.64 & $\mathrm{Up}$ & 0.05 \\
\hline 9 & 9.93 & 570.3519 & $\mathrm{C}_{30} \mathrm{H}_{52} \mathrm{NO}_{7} \mathrm{P}$ & LPC 22:5 & 1.37 & $\mathrm{Up}$ & 0.01 \\
\hline 10 & 10.69 & 524.3707 & $\mathrm{C}_{26} \mathrm{H}_{54} \mathrm{NO}_{7} \mathrm{P}$ & LPC 18:0 & 4.20 & $\mathrm{Up}$ & 0.01 \\
\hline 11 & 9.21 & 454.2925 & $\mathrm{C}_{21} \mathrm{H}_{44} \mathrm{NO}_{7} \mathrm{P}$ & LPE 16:0 & 11.38 & $\mathrm{Up}$ & 0.01 \\
\hline 12 & 10.4 & 482.3241 & $\mathrm{C}_{23} \mathrm{H}_{44} \mathrm{NO}_{7} \mathrm{P}$ & LPE 18:2 & 5.25 & $\mathrm{Up}$ & 0.01 \\
\hline 13 & 14.43 & 728.5217 & Unknown & PC 32:3 & 2.94 & $\mathrm{Up}$ & 0.01 \\
\hline 14 & 15.54 & 756.55 & Unknown & PC 34:3 & 11.13 & $\mathrm{Up}$ & 0.01 \\
\hline 15 & 15.72 & 744.5532 & $\mathrm{C}_{41} \mathrm{H}_{78} \mathrm{NO}_{8} \mathrm{P}$ & PC 33:2 & 0.42 & Down & 0.01 \\
\hline 16 & 15.91 & 732.5531 & $\mathrm{C}_{40} \mathrm{H}_{78} \mathrm{NO}_{8} \mathrm{P}$ & PC 32:1 & 2.78 & $\mathrm{Up}$ & 0.01 \\
\hline 17 & 16.18 & 808.5834 & Unknown & PC 38:5 & 12.88 & Up & 0.01 \\
\hline 18 & 16.38 & 734.5591 & $\mathrm{C}_{42} \mathrm{H}_{80} \mathrm{NO}_{8} \mathrm{P}$ & PC 32:0 & 0.79 & Down & 0.01 \\
\hline 19 & 15.91 & 764.5212 & Unknown & PE 38:6 & 93.36 & Up & 0.01 \\
\hline 20 & 16.17 & 748.5265 & Unknown & PE 38:7 & 13.76 & $\mathrm{Up}$ & 0.01 \\
\hline 21 & 16.74 & 768.5526 & Unknown & PE 38:4 & 13.44 & Up & 0.01 \\
\hline 22 & 9.81 & 185.1547 & $\mathrm{C}_{11} \mathrm{H}_{22} \mathrm{O}_{3}$ & FA11:0 & 1.84 & $\mathrm{Up}$ & - \\
\hline 23 & 11.63 & 225.1854 & Unknown & FA 14:1 & 3.43 & Up & 0.01 \\
\hline 24 & 12.43 & 275.2021 & Unknown & FA 18:4 & 5.15 & Up & 0.01 \\
\hline 25 & 12.44 & 251.2023 & Unknown & FA16:2 & 3.88 & $\mathrm{Up}$ & 0.01 \\
\hline 26 & 13.06 & 277.2168 & $\mathrm{C}_{18} \mathrm{H}_{3} \mathrm{O}_{2}$ & FA $18: 3$ & 3.68 & $\mathrm{Up}$ & 0.01 \\
\hline 27 & 13.72 & 279.2331 & $\mathrm{C}_{18} \mathrm{H}_{32} \mathrm{O}_{2}$ & FA 18:2 & 209 & Up & - \\
\hline 28 & 13.81 & 303.2327 & $\mathrm{C}_{20} \mathrm{H}_{32} \mathrm{O}_{2}$ & FA 20:4 & 1.20 & $\mathrm{Up}$ & - \\
\hline 29 & 16.03 & 311.2946 & $\mathrm{C}_{22} \mathrm{H}_{40} \mathrm{O}_{2}$ & FA 20:0 & 1.11 & $\mathrm{Up}$ & - \\
\hline 30 & 16.73 & 339.3272 & $\mathrm{C}_{22} \mathrm{H}_{44} \mathrm{O}_{2}$ & FA 22:0 & 1.04 & $\mathrm{Up}$ & - \\
\hline 31 & 17.37 & 367.3565 & $\mathrm{C}_{24} \mathrm{H}_{48} \mathrm{O}_{2}$ & FA 24:0 & 1.04 & Up & - \\
\hline 32 & 14.2 & 675.5406 & Unknown & SM 32:1 & 2.27 & $\mathrm{Up}$ & 0.01 \\
\hline 33 & 15.07 & 703.5728 & Unknown & SM 34:1 & 1.36 & Up & 0.01 \\
\hline 34 & 0.72 & 89.0246 & $\mathrm{C}_{3} \mathrm{H}_{6} \mathrm{O}_{3}$ & Lactic acid & 7.73 & $\mathrm{Up}$ & 0.05 \\
\hline 35 & 5.59 & 314.2326 & Unknown & Carnitine C10:1 & 1.30 & Up & 0.01 \\
\hline 36 & 8.62 & 398.3265 & Unknown & Carnitine C16:1 & 2.51 & Up & 0.01 \\
\hline 37 & 7.69 & 370.2952 & unknown & Carnitine C14:1 & 5.89 & Up & 0.01 \\
\hline 38 & 0.8 & 167.0205 & $\mathrm{C}_{5} \mathrm{H}_{4} \mathrm{~N}_{4} \mathrm{O}_{3}$ & Uric acid & 1.10 & Up & 0.05 \\
\hline 39 & 0.81 & 114.0565 & $\mathrm{C}_{5} \mathrm{H}_{9} \mathrm{NO}_{2}$ & Proline & 1.79 & Up & 0.05 \\
\hline 40 & 3.15 & 212.0029 & $\mathrm{C}_{8} \mathrm{H}_{7} \mathrm{NO}_{4} \mathrm{~S}$ & Indoxyl sulfate & 37.57 & $\mathrm{Up}$ & 0.05 \\
\hline 41 & 3.36 & 203.0837 & $\mathrm{C}_{11} \mathrm{H}_{12} \mathrm{~N}_{2} \mathrm{O}_{2}$ & Tryptophan & 1.26 & $\mathrm{Up}$ & 0.01 \\
\hline 42 & 9.07 & 391.2846 & $\mathrm{C}_{24} \mathrm{H}_{40} \mathrm{O}_{4}$ & UDCA & 2.12 & $\mathrm{Up}$ & 0.01 \\
\hline 43 & 11.23 & 498.2895 & $\mathrm{C}_{26} \mathrm{H}_{45} \mathrm{NO}_{6} \mathrm{~S}$ & TDCA & 36.54 & $\mathrm{Up}$ & 0.01 \\
\hline 44 & 11.23 & 391.2846 & $\mathrm{C}_{32} \mathrm{H}_{51} \mathrm{NO}_{11}$ & CDCA & 8.80 & Up & 0.01 \\
\hline 45 & 3.33 & 283.0818 & $\mathrm{C}_{13} \mathrm{H}_{16} \mathrm{O}_{7}$ & P-cresol glucuronide & 14.12 & Up & 0.01 \\
\hline 46 & 1.06 & 166.0863 & $\mathrm{C}_{9} \mathrm{H}_{11} \mathrm{NO}_{2}$ & Phenylalanine & 0.24 & Down & 0.01 \\
\hline
\end{tabular}

Comparisons were made with hyperuricemia group. -, no significance. tR, retention time; LPC, lysophosphatidylcholine; LPE, lysophosphatidylethanolamine; PC, phosphatidylcholine; PE, phosphatidyl ethanolamine; FA, fatty acid; SM, sphingomyelin; UDCA, ursodeoxycholic acid; CDCA, chenodeoxycholic acid; TDCA, tauroursodeoxycholic acid. 


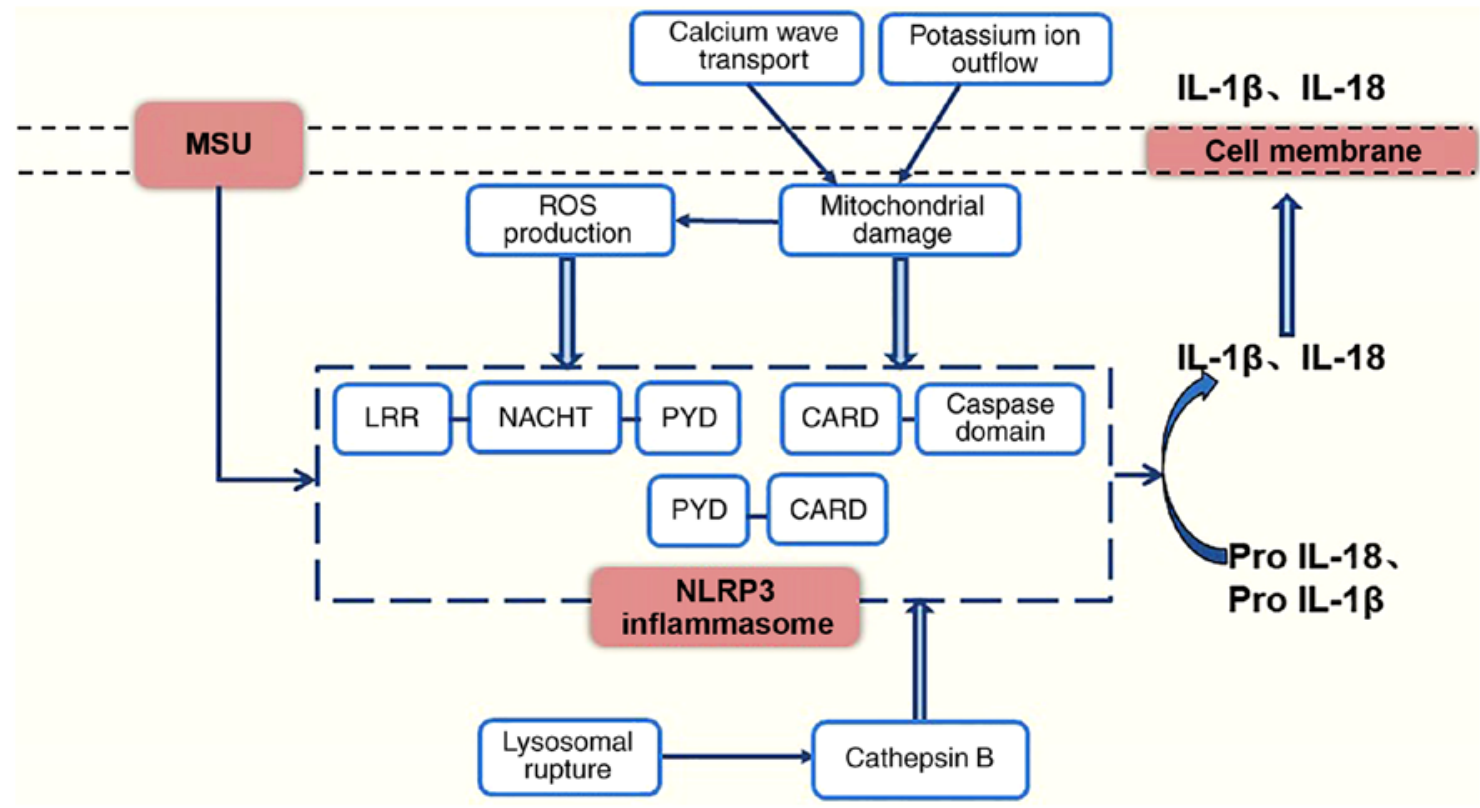

Figure 5. Model for the activation of the NLRP3 inflammasome. NLRP3, NOD-like receptor protein 3; MSU, monosodium urate; ROS, reactive oxygen species; TRX, thioredoxin; TXNIP, thioredoxin-interacting protein; mtDNA, mitochondrial DNA; IL-1 $\beta$, interleukin-1 $\beta$; IL-18, interleukin-18; LRR, leucine-rich-repeat domain; NACHT, nucleotide binding domain; PYD, pyrin domain; CARD, caspase recruitment domain.

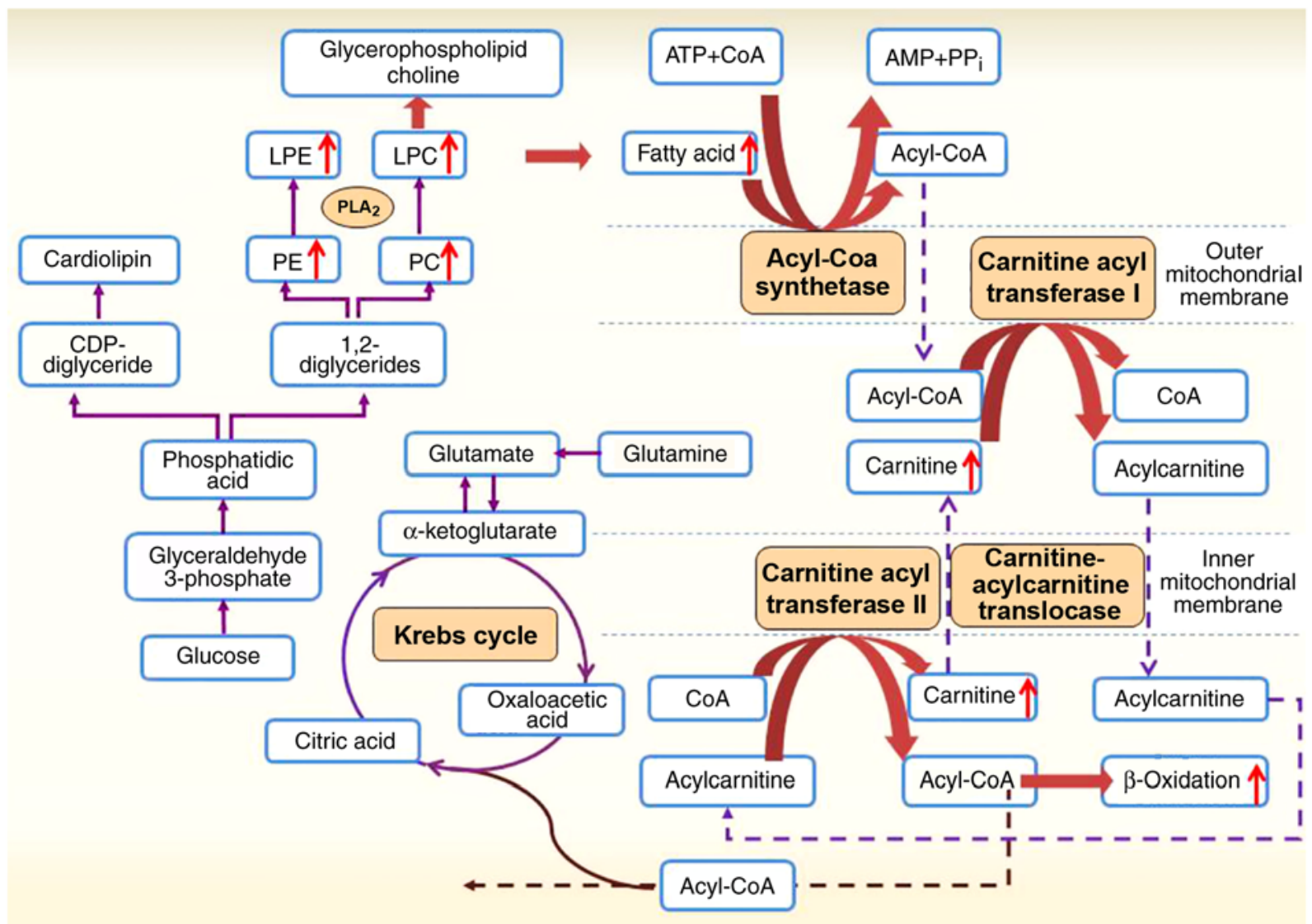

Figure 6. Lipid metabolism pathways. LPC, lysophosphatidylcholine; LPE, lysophosphatidylethanolamine; PC, phosphatidylcholine; PE, phosphatidyl ethanolamine; PLA2, phospholipase A2; Acyl-CoA, acyl-coenzyme A; PPi, inorganic pyrophosphate.

which indirectly suggested the potential association between the NLRP3 inflammasome and blood glucose. The level of lactic acid was upregulated, which suggested the increased activity of glycolysis in glucose metabolism. In the process of glycolysis, the first enzyme to metabolize fructose is fructokinase, also known as ketohexokinase (KHK). The 
metabolism of fructose to fructose-1-phosphate by KHK occurs primarily in the liver and results in a decrease in intracellular phosphate and ATP levels. The decrease in intracellular phosphate stimulates AMP deaminase, which catalyses the degradation of AMP to inosine monophosphate and eventually uric acid (50). A previous study suggested that fructose mediated the generation of uric acid in diabetes and obesity (50). In the present study, the increased levels of blood glucose, NLRP3 inflammasome component expression and lactic acid in gouty nephropathy group indicated an increase in glucose metabolism, which may lead to upregulated uric acid levels and promotion of the development of gouty nephropathy. However, other metabolites of glucose metabolism were not detected, and further investigation is required to reveal the association between gouty nephropathy and glucose metabolism.

In the present study, the expression of the NLRP3 inflammasome components in peripheral blood mononuclear cells and the levels of IL-1 $\beta$ and IL-18 in plasma were significantly increased in patients with gouty nephropathy, which suggested that the NLRP3 inflammasome served a pivotal role in the progression of gouty nephropathy. In addition, there was an increased expression of lipid metabolism in gouty nephropathy, and analysis of the changes of the levels of 46 metabolites in plasma indicated that lipids may mediate the progression of gouty nephropathy through the activity of PLA2, $\beta$-oxidation and activation of the NLRP3 inflammasome.

\section{Acknowledgements}

Not applicable.

\section{Funding}

The present study was supported by the Fundamental Research Project of Shenzhen Science and Technology Research and Development Funds (grant no. JCYJ20160427191440905).

\section{Availability of data and materials}

The datasets used and/or analyzed during the current study are available from the corresponding author on reasonable request.

\section{Authors' contributions}

YZZ and XLS designed the experiments, analysed the data and wrote the manuscript. YPX and YZZ performed the experiments. FJG and ASZ analysed and interpreted the data. JHC contributed to the design of the experimental methods, and wrote the manuscript, approved the version to be published and agreed to be accountable for all aspects of the work. All authors read and approved the final manuscript.

\section{Ethics approval and consent to participate}

The study was approved by the Ethics Committee of the Affiliated Bao'an Hospital of Shenzhen and written informed consent was obtained from all participants.

\section{Patient consent for publication}

Written informed consent was obtained from all participants.

\section{Competing interests}

The authors declare that they have no competing interests.

\section{References}

1. Saito I, Saruta T, Kondo K, Nakamura R, Oguro T, Yamagami K, Ozawa Y and Kato E: Serum Uricd acidand the renin-angiotensin system in hypertention. J Am Geriatr Soc 26: 241-247, 1978.

2. Ghaemi-Oskouie F and Shi Y: The role of Uric acid as an endogenous danger signal in immunity and inflammation. Curr Rheumatol Rep 13: 160-166, 2011.

3. Yao Y, Chen S, Cao M, Fan X, Yang T, Huang Y, Song X, Li Y, Ye L, Shen N, et al: Antigen-specific $\mathrm{CD}^{+} \mathrm{T}$ cell feedback activates NLRP3 inflammasome in antigen-presenting cells through perforin. Nat Commun 8: 15402, 2017.

4. Abderrazak A, Syrovets T, Couchie D, El Hadri K, Friguet B, Simmet T and Rouis M: NLRP3 inflammasome: From a danger signal sensor to a regulatory node of oxidative stress and inflammatory diseases. Redox Biol 4: 296-307, 2015.

5. Wu R, Liu X, Yin J, Wu H, Cai X, Wang N, Qian Y and Wang F: IL-6 receptor blockade ameliorates diabetic nephropathy via inhibiting inflammasome in mice. Metab Clin Exp 83: 18-24, 2018.

6. Gonçalves JP, Oliveira A, Severo M, Santos AC and Lopes C: Cross-sectional and longitudinal associations between serum uric acid and metabolic syndrome. Endocrine 41: 450-457, 2012.

7. Borghi C, Rosei EA, Bardin T, Dawson J, Dominiczak A Kielstein JT, Manolis AJ, Perez-Ruiz F and Mancia G: Serum uric acid and the risk of cardiovascular and renal disease. J Hypertens 33: 1729-1741, 2015.

8. Stamp LK and Chapman PT: Gout and its comorbidities: Implications for therapy. Rheumatology (Oxford) 52: 34-44, 2013.

9. Chen JH, Yeh WT, Chuang SY, Wu YY and Pan WH: Gender-specific risk factors for incident gout: A prospective cohort study. Clin Rheumatol 31: 239-245, 2012.

10. Yu X, Chen K and Tong Y: Lipid metabolism study of hyperuricemia and gout arthritis based on lipidomics technology. World Latest Med Info 7: 30-31, 2016.

11. Vázquez-Mellado J, Hernández-Cuevas CB, AlvarezHernández E, Ventura-Rios L, Peláez-Ballestas I, Casasola-Vargas J, García-Méndez S and Burgos-Vargas R: The diagnostic value of the proposal for clinical gout diagnosis (CGD). Clin Rheumatol 31: 429-434, 2012.

12. Wallace SL, Robinson H, Masi AT, Decker JL, McCarty DJ and Yü TF: Preliminary criteria for the classification of the acute arthritis of primary gout. Arthritis Rheum 20: 895-900, 1977.

13. Livak KJ and Schmittgen TD: Analysis of relative gene expression data using real-time quantitative PCR and the 2(-Delta Delta C(T)) method. Methods 25: 402-408, 2001.

14. Zhao X, Zeng Z, Chen A, Lu X, Zhao C, Hu C, Zhou L, Liu X, Wang X, Hou X, et al: Comprehensive strategy to construct in-house database for accurate and batch identification of small molecular metabolites. Anal Chem 90: 7635-7643, 2018.

15. Liu T, Li S, Tian X, Li Z, Cui Y, Han F, Zhao Y and Yu Z: A plasma metabonomic analysis on potential biomarker in pyrexia induced by three methods using ultra high performance liquid chromatography coupled with Fourier transform ion cyclotron resonance mass spectrometry. J Chromatogr B Analyt Technol Biomed Life Sci 1063: 214-225, 2017.

16. Heneka MT, Kummer MP, Stutz A, Delekate A, Schwartz S, Vieira-Saecker A, Griep A, Axt D, Remus A, Tzeng TC, et al: NLRP3 is activated in Alzheimer's disease and contributes to pathology in APP/PS1 mice. Nature 493: 674-678, 2013.

17. Kim SM, Lee SH, Kim YG, Kim SY, Seo JW, Choi YW, Kim DJ, Jeong KH, Lee TW, Ihm CG, et al: Hyperuricemia-induced NLRP3 activation of macrophages contributes to the progression of diabetic nephropathy. Am J Physiol Renal Physiol 308: F993-F1003, 2015.

18. Zheng F, Xing S, Gong Z and Xing Q: NLRP3 inflammasomes show high expression in aorta of patients with atherosclerosis. Heart Lung Circ 22: 746-750, 2013. 
19. Csak T, Ganz M, Pespisa J, Kodys K, Dolganiuc A and Szabo G: Fatty acid and endotoxin activate inflammasomes in mouse hepatocytes that release danger signals to stimulate immune cells. Hepatology 54: 133-144, 2011.

20. Gao L, Shen F and LI YS: Effects of NLRP3 inflammasome on cerebral ischemia-reperfusion injury. J Shanghai Jiaotong Univ Med Sci 35: 1896-1899, 2015 (In Chinese).

21. Braga TT, Forni MF, Correa-Costa M, Ramos RN, Barbuto JA, Branco P, Castoldi A, Hiyane MI, Davanso MR, Latz E, et al: Soluble Uric acid activates the NLRP3 inflammasome. Sci Rep 7: 39884, 2017.

22. Zhou R, Tardivel A, Thorens B, Choi I and Tschopp J: Thioredoxin-interacting protein links oxidative stress to inflammasome activation. Nat Immunol 11: 136-140, 2010.

23. Bruchard M, Mignot G, Derangère V, Chalmin F, Chevriaux A, Végran F, Boireau W, Simon B, Ryffel B, Connat JL, et al: Chemotherapy-triggered cathepsin B release in myeloid-derived suppressor cells activates the Nlrp3 inflammasome and promotes tumor growth. Nat Med 19: 57-64, 2013.

24. Shimada K, Crother TR, Karlin J, Dagvadorj J, Chiba N, Chen S, Ramanujan VK, Wolf AJ, Vergnes L, Ojcius DM, et al: Oxidized mitochondrial DNA activates the NLRP3 inflammasome during apoptosis. Immunity 36: 401-414, 2012.

25. Wang R, Wang Y, Mu N, Lou X, Li W, Chen Y, Fan D and Tan H: Activation of NLRP3 inflammasomes contributes to hyperhomocysteinemia-aggravated inflammation and atherosclerosis in apoE-deficient mice. Lab Invest 97: 922-934, 2017.

26. Hornung V, Bauernfeind F, Halle A,Samstad EO, Kono H, Rock KL, Fitzgerald KA and LatzE: Silica crystals and aluminum salts activate the NALP3 inflammasome through phagosomal destabilization. Nat Immunol 9: 847-856, 2008

27. Lee GS, Subramanian N, Kim AI, Aksentijevich I, Goldbach-Mansky R, Sacks DB, Germain RN, Kastner DL and Chae JJ: The calcium-sensing receptor regulates the NLRP3 inflammasome through $\mathrm{Ca} 2+$ and cAMP. Nature 492: 123-127, 2012.

28. Ives A, Nomura J, Martinon F, Roger T, LeRoy D, Miner JN, Simon G, Busso N and So A: Xanthine oxidoreductase regulates macrophage IL1 $\beta$ secretion upon NLRP3 inflammasome activation. Nat Commun 6: 6555, 2015.

29. Rhee EP: Metabolomics and renal disease. Curr Opin Nephrol Hypertens 24: 371-379, 2015

30. Zhao YY, Cheng XL, Lin RC and Wei F: Lipidomics applications for disease biomarker discovery in mammal models. Biomark Med 9: 153-168, 2015.

31. Sekula P, Goek ON, Quaye L, Barrios C, Levey AS, Römisch-Margl W, Menni C, Yet I, Gieger C, Inker LA, et al: A metabolome-wide association study of kidney function and disease in the general population. J Am Soc Nephrol 27: $1175-1188,2016$

32. Makide K, Kitamura H, Sato Y, Okutani M and Aoki J: Emerging lysophospholipid mediators, lysophosphatidylserine, lysophosphatidylthreonine, lysophosphatidylethanolamine and lysophosphatidylglycerol. Prostaglandins Other Lipid Mediat 89: 135-139, 2009.

33. Zhang ZH, Vaziri ND, Wei F, Cheng XL, Bai X and Zhao YY: An integrated lipidomics and metabolomics reveal nephroprotective effect and biochemical mechanism of Rheum officinale in chronic renal failure. Sci Rep 6: 22151, 2016.

34. Zhao YY, Vaziri ND and Lin RC: Lipidomics: New insight into kidney disease. Adv Clin Chem 68: 153-175, 2015.

35. Chen DQ, Chen H, Chen L, Vaziri ND, Wang M, Li XR and Zhao YY: The link between phenotype and fatty acid metabolism in advanced chronic kidney disease. Nephrol Dial Transplant 32 1154-1166, 2017.
36. Tsoukalas D, Alegakis AK, Fragkiadaki P, Papakonstantinou E, Tsilimidos G, Geraci F, Sarandi E, Nikitovic D, Spandidos DA and Tsatsakis A: Application of metabolomics part II: Focus on fatty acids and their metabolites in healthy adults. Int $\mathrm{J}$ Mol Med 43: 233-242, 2019.

37. Pappa V, Seydel K, Gupta S, Feintuch CM, Potchen MJ, Kampondeni S, Goldman-Yassen A, Veenstra M, Lopez L, Kim RS, et al: Lipid metabolites of the phospholipase A2 pathway and inflammatory cytokines are associated with brain volume in paediatric cerebral malaria. Malar J 14: 513, 2015.

38. Zhang S, Zhuang J, Yue G, Wang Y, Liu M, Zhang B, Du Z and Ma Q: Lipidomics to investigate the pharmacologic mechanisms of ginkgo folium in the hyperuricemic rat model. J Chromatogr B Analyt Technol Biomed Life Sci 1060: 407-415, 2017.

39. Yadav D, Lee ES, Kim HM, Lee EY, Choi E and Chung CH: Hyperuricemia as a potential determinant of metabolic syndrome. J Lifestyle Med 3: 98-106, 2013.

40. Pazos Pérez F: Uric acid renal lithiasis: New concepts. Contrib Nephrol 192: 116-124, 2018.

41. Iyer SS, He Q, Janczy JR, Elliott EI, Zhong Z, Olivier AK, Sadler JJ, Knepper-Adrian V, Han R, Qiao L, et al: Mitochondrial cardiolipin is required for Nlrp3 inflammasome activation. Immunity 39: 311-323, 2013.

42. Jiang Y, Wang M, Huang K, Zhang Z, Shao N, Zhang Y, Wang W and Wang S: Oxidized low-density lipoprotein induces secretion of interleukin-1 $\beta$ by macrophages via reactive oxygen species-dependent NLRP3 inflammasome activation. Biochem Biophys Res Commun 425: 121-126, 2012.

43. Duewell P, Kono H, Rayner KJ, Sirois CM, Vladimer G, Bauernfeind FG, Abela GS, Franchi L, Nuñez G, Schnurr M, et al: NLRP3 inflamasomes are required for atherogenesis and activated by cholesterol crystals. Nature 464: 1357-1361, 2010.

44. Lin SJ, Yen HT, Chen YH, Ku HH, Lin FY and Chen YL: Expression of interleukin-1 beta and interleukin-1 receptor antagonist in oxLDL-treated human aortic smooth muscle cells and in the neointima of cholesterol-fed endothelia-denuded rabbits. J Cell Biochem 88: 836-847, 2010.

45. Oury C: CD36: Linking lipids to the NLRP3 inflammasome, atherogenesis and atherothrombosis. Cell Mol Immunol 11: 8-10, 2014.

46. Johnson RJ, Nakagawa T, Sanchez-Lozada LG, Shafiu M, Sundaram S, Le M, Ishimoto T, Sautin YY and Lanaspa MA: Sugar, uric acid, and the etiology of diabetes and obesity. Diabetes 62: 3307-3315, 2013

47. Lanaspa MA, Sanchez-Lozada LG, Cicerchi C, Li N, Roncal-Jimenez CA, Ishimoto T, Le M, Garcia GE, Thomas JB, Rivard CJ, et al: Uric acid stimulates fructokinase and accelerates fructose metabolism in the development of fatty liver. PLoS One 7: e47948, 02012.

48. Yang CS, Shin DM and Jo EK: The role of NLR-related protein 3 inflammasome in host defense and inflammatory diseases. Int Neurourol J 16: 2-12, 2012.

49. Halle A, Hornung V, Petzold GC, Stewart CR, Monks BG, Reinheckel T, Fitzgerald KA, Latz E, Moore KJ and Golenbock DT: The nalp3 inflammasome is involved in the innate immune response to amyloid-beta. Nat Immunol 9: 857-865, 2008

50. Emmerson BT: Effect of oral fructose on urate production. Ann Rheum Dis 33: 276-280, 1974.

This work is licensed under a Creative Commons Attribution-NonCommercial-NoDerivatives 4.0 International (CC BY-NC-ND 4.0) License. 